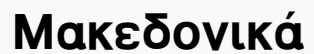

Tóp. 4, Ap. 1 (1960)

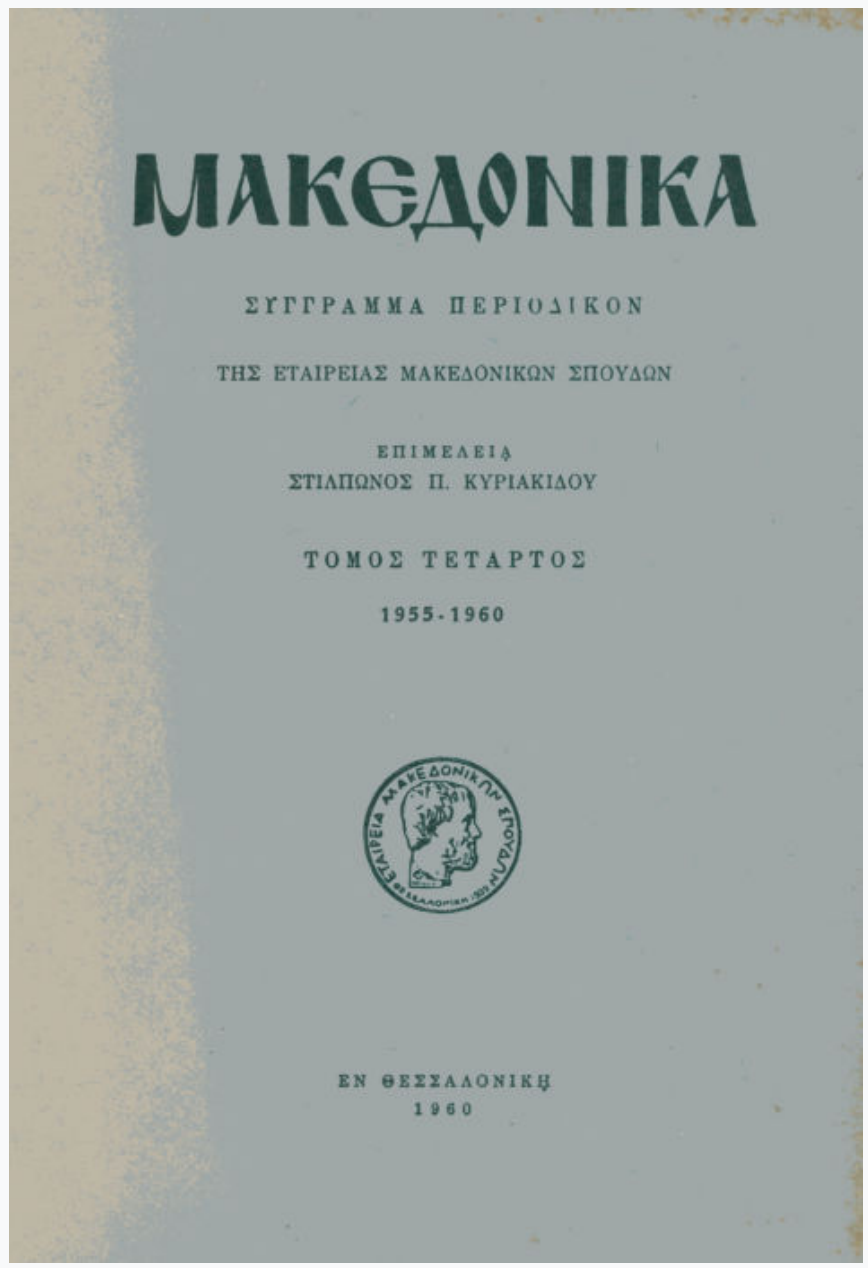

\section{Romania, Stephen Fischer Galati editor}

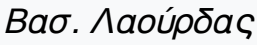

doi: $10.12681 /$ makedonika.761

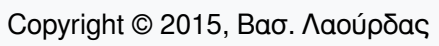

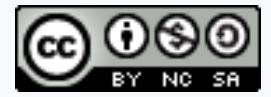

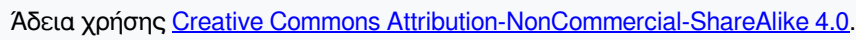

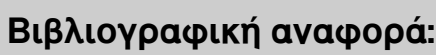

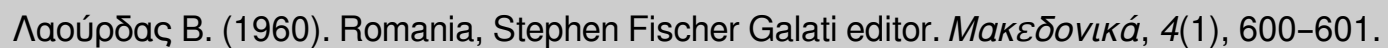
https://doi.org/10.12681/makedonika.761 


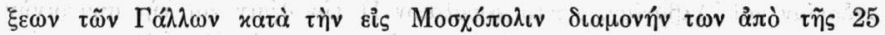

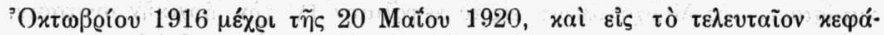
$\lambda \alpha \iota$ เ

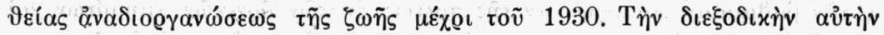

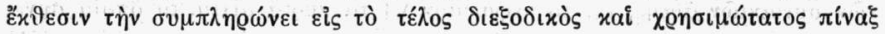
o̊voứ̛ $\omega v$.

BAE. NAOYPAAE

R o ma nia, Stephen Fischer Galati editor. Mid - European Studies Center of the Free Europe Committee lnc. 1957, $\sigma \varepsilon \lambda .399$.

' $O$ '็ร åv

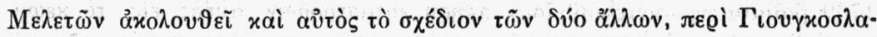

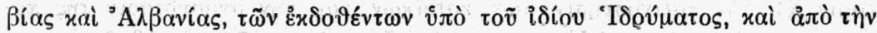

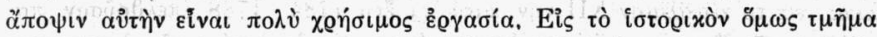

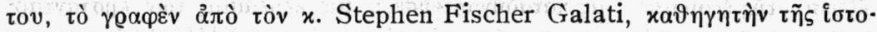

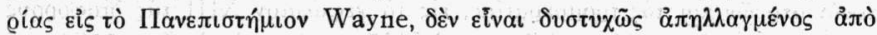

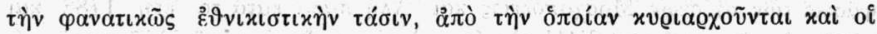

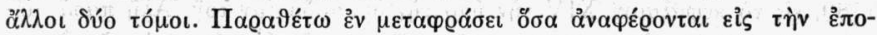

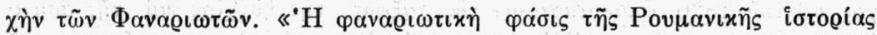

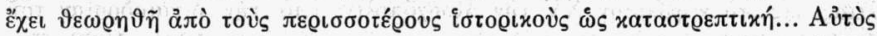

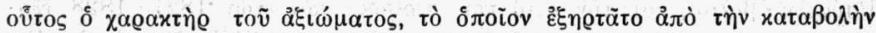

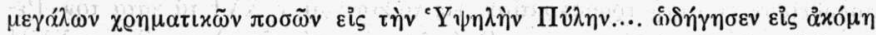

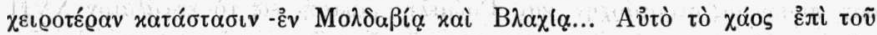

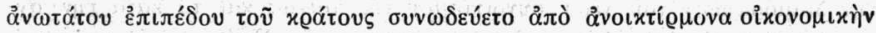

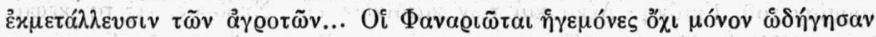

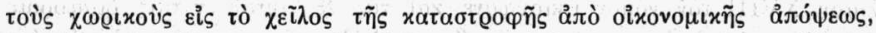

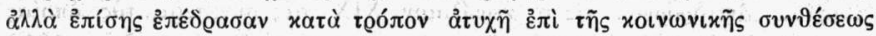

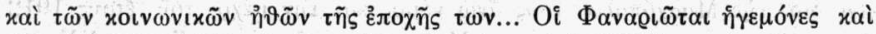

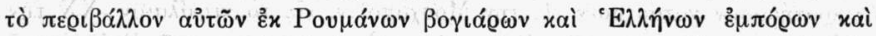

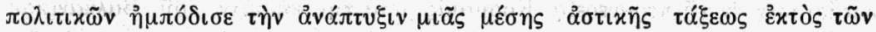

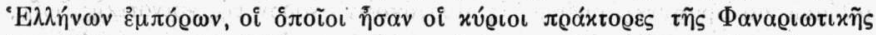

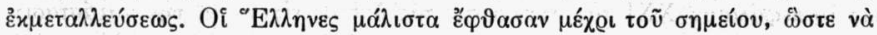

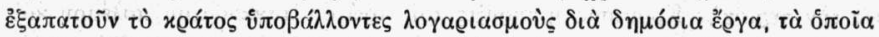

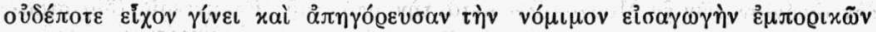

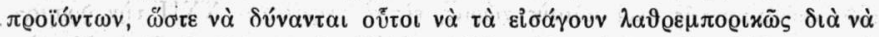

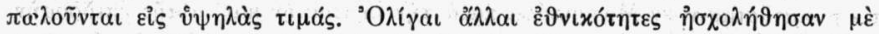

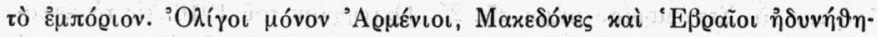

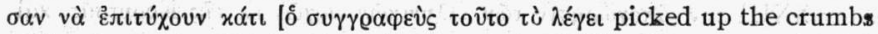

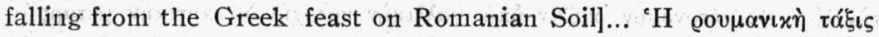

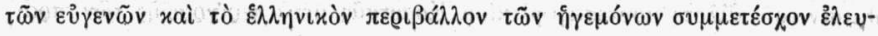




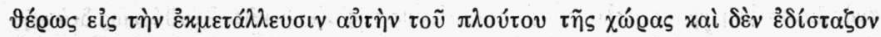

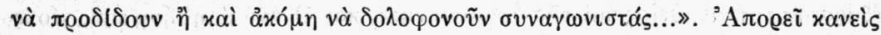

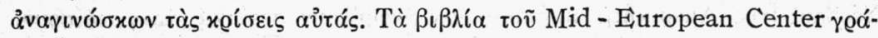

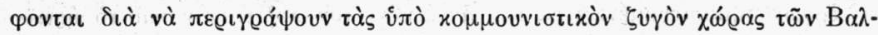

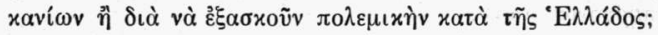

BAE. NAOYPAAE

Djok o Slijepcevic', The Macedonian Question. The Struggle for Southern Serbia. Translated by James Larkin. The American Institute for Balkan Affairs, Chicago, Illinois, 1959, $\sigma \varepsilon \lambda .267$.

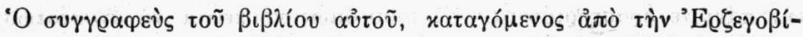

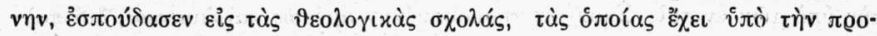

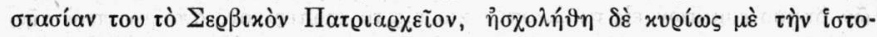

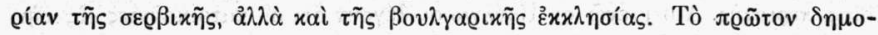

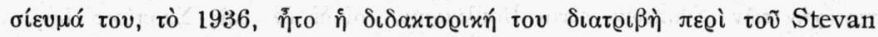

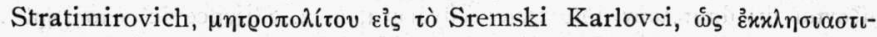

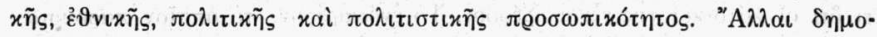

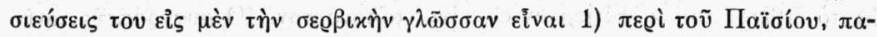

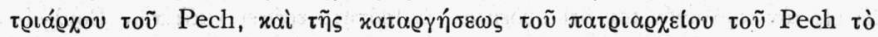

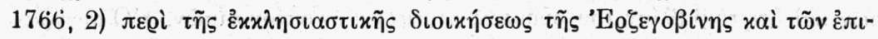

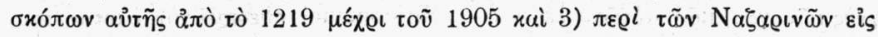

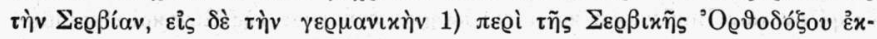

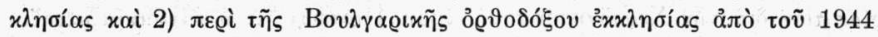

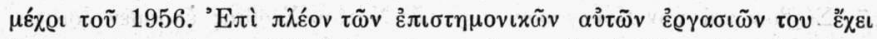

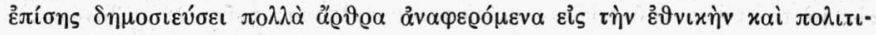

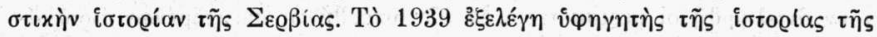

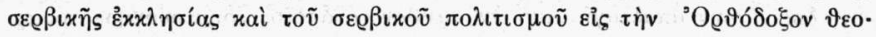

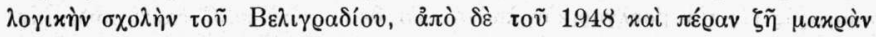

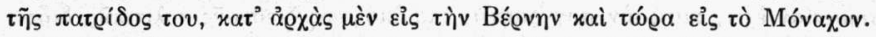

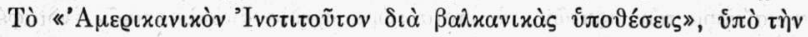

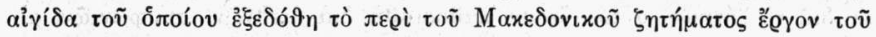

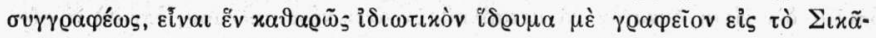

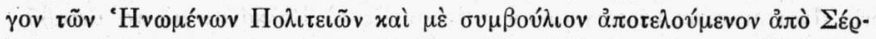

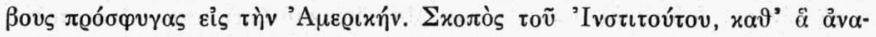

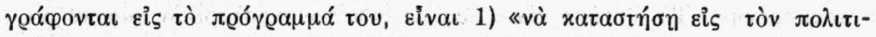

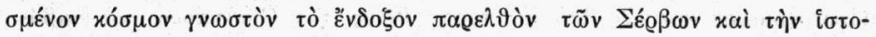

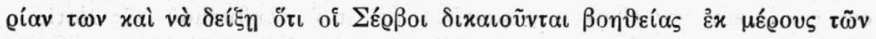

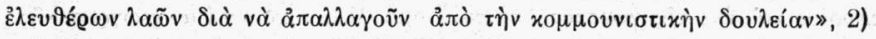

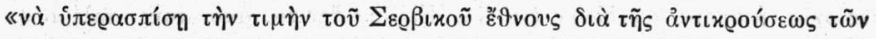

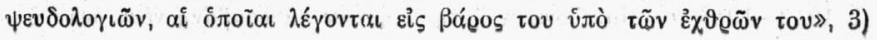

